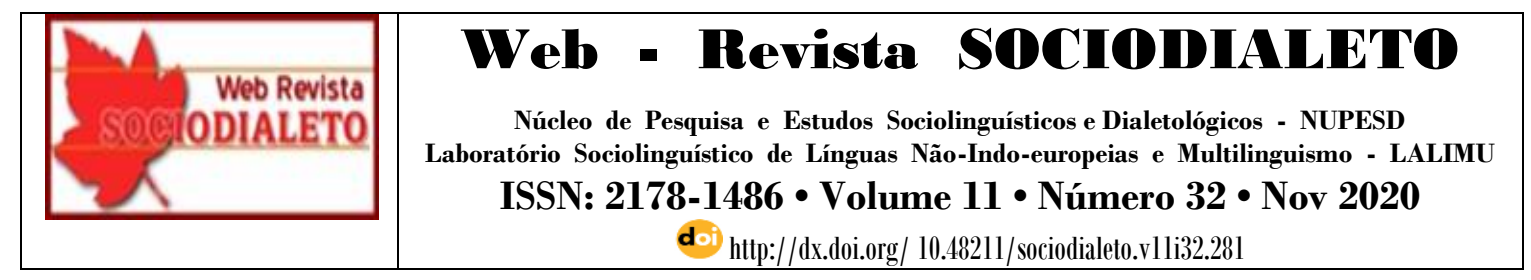

\title{
CONTATO ENTRE LÍNGUAS: ANÁLISE DE CARTAZES DE VENEZUELANOS REFUGIADOS NA CIDADE DE CUIABÁ-MT
}

\author{
Ivanete Maria de Jesus (PPGEL/UFMT $)^{1}$ \\ iva2202@hotmail.com \\ Rayane Thaynara Santos (PPGEL/UFMT) $)^{2}$ \\ rayanethaynara@hotmail.com \\ Áurea Cavalcante Santana (PPGEL/UFMT) $)^{3}$ \\ aurearsh@yahoo.com.br
}

\begin{abstract}
RESUMO: Este trabalho se propõe a retratar a situação dos venezuelanos refugiados na cidade de Cuiabá, Mato Grosso. Como metodologia nos respaldamos em um estudo teórico sobre a sociolinguística, por meio de um levantamento de dados coletados através de entrevistas e cartazes utilizados pelos venezuelanos espalhados pela cidade. Desta forma, será feito a análise das características ortográficas observadas na escrita dos cartazes, além dos fatores que os levaram a utilizar determinada escrita, uma vez que eles ainda não têm total domínio do idioma brasileiro. Com base nos pressupostos teórico na Sociolinguística que é uma das subáreas da Linguística que estuda a língua em uso dentro da comunidade de fala, conforme (CALVET, 2002, LABOV, 2008).
\end{abstract}

PALAVRAS-CHAVE: Sociolinguística, Venezuelanos, Fato Social.

ABSTRACT: This paper aims to portray the situation of Venezuelan refugees in the city of Cuiabá, Mato Grosso. As methodology we are supported on a theoretical study on sociolinguistics, through a survey of collected data through interviews and posters used by Venezuelans throughout the city. In this way, the analysis of the orthographic characteristics observed in the writing of the posters will be made, in addition to the factors that led them to use certain writing, since they still do not have full command of the Brazilian language. Based on the theoretical assumptions in sociolinguistics which is one of the sub-areas of linguistics that studies the language in use within the speech community, as (CALVET, 2002, LABOV, 2008).

KEYWORDS: Sociolinguistics, Venezuelans, Social Fact.

\footnotetext{
${ }^{1}$ Doutoranda do Programa de Pós-Graduação em Estudos de Linguagem-PPGEL/UFMT, sob orientação da Profa. Dra. Áurea Cavalcante Santana, Profa. Dra. Carolina Akie Ochiai Seixas Lima.

${ }^{2}$ Mestranda do Programa de Pós-Graduação em Estudos de Linguagem-PPGEL/UFMT, sob orientação da Profa. Dra. Carolina Akie Ochiai Seixas Lima.

${ }^{3}$ Pesquisadora Associada e Professora do Programa de Pós-Graduação em Estudos da Linguagem da Universidade Federal de Mato Grosso (PPGEL/UFMT). Coordenadora do grupo de pesquisa Estudos, Descrição e Documentação de Línguas Indígenas (GEDDELI).
} 


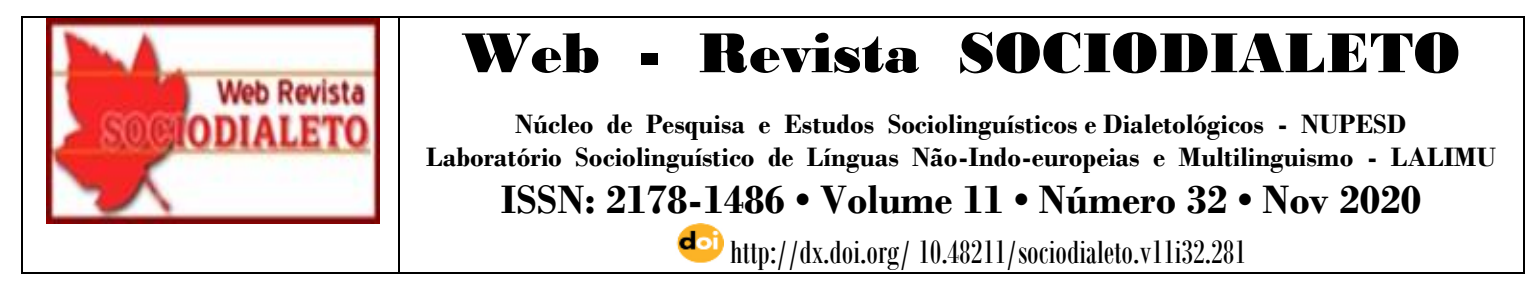

\section{INTRODUÇÃO}

A partir da década de 60 a língua como fato social ganha espaço, explicada pela mudança social, ou seja, por mudanças externas. A Sociolinguística é uma área da linguística que estuda as relações entre língua e sociedade e dá ênfase ao caráter institucional das línguas (CALVET, 2002).

No que tange a Sociolinguística, temos como principal pesquisador William Labov que questiona e propõe um novo olhar sobre as estruturas da língua e presença do componente social na análise linguística (LABOV,2008).

A Sociolinguística tem como questões norteadora a variação e mudança linguística, o bilinguismo, contato linguístico, língua minoritárias e política e planejamento linguístico (CALVET, 2002; LABOV, 2008).

Segundo Mollica (2008, p.11),

Cabe à Sociolinguística investigar o grau de estabilidade ou de mutabilidade da variação, diagnosticar as variáveis que têm efeito positivo ou negativo sobre a emergência dos usos linguísticos alternativos e prever seu comportamento regular e sistemático.

Para realizarmos uma análise adequada das variações e/ou de aspectos linguísticos específicos precisamos conhecer os informantes. Na escolha de informantes e na coleta de dados o inquérito se torna muito importante para que tenhamos os dados com a menor interferência possível do pesquisador.

Sobre isso Cardoso (2010) apresenta os tipos de variações e variáveis que nos auxiliam a desenvolver um bom inquérito. As variações podem ser diatópicas (regional), que se refere ao espaço geográfico; diastrática (social), que inclui informações sobre grau de escolaridade, nível socioeconômico, gênero e faixa etária; diafásica (estilística), leva em consideração o momento que a fala ocorreu.

Assim, partindo do entendimento que a Sociolinguística estuda a língua e sua relação social torna-se necessário compreendermos os aspectos históricos e sociais 


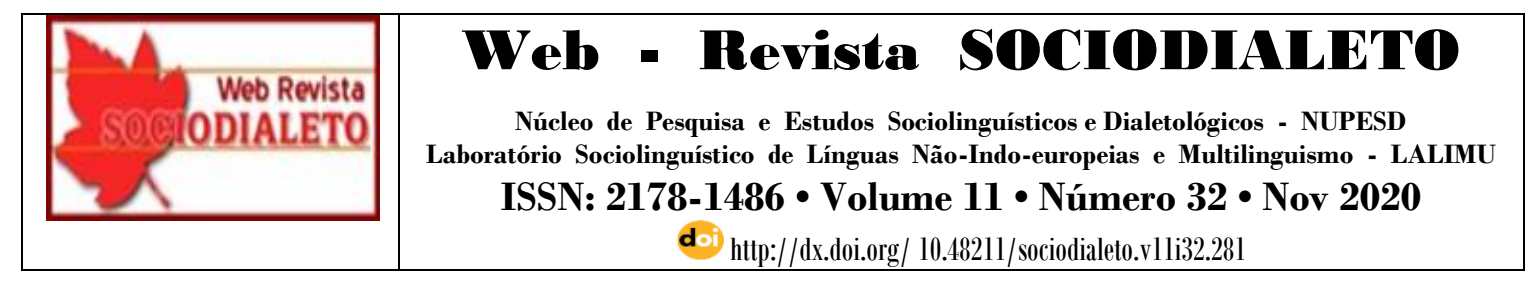

envolvidos no processo de migração dos venezuelanos para o Brasil para então desenvolvermos as análises de cartazes de venezuelanos nas ruas de Cuiabá, MT, propostas por este artigo.

Neste artigo faremos uma análise da ortografia de três cartazes produzidos por venezuelanos refugiados na cidade de Cuiabá-MT. A escolha por esse material para análise se dá pelo grande número de Venezuelanos nas ruas da cidade portando esse instrumento de comunicação.

Além dessa análise realizamos uma entrevista, de cunho descritivo e qualitativo, na pastoral do migrante para conhecermos os nossos informantes e entendermos sua realidade antes de virem para nosso país bem como o porquê escolheram o uso de cartazes para se mostrarem na sociedade.

\section{Contextualizando}

A Venezuela tem passado nos últimos anos por uma longa crise política e socioeconômica. Segundo Vaz (2016, p. 1) essa crise tem como influência três fatores fundamentais: lugar, o comprometimento da condição de governabilidade, a crescente deterioração da condição econômica, e o aprofundamento e a generalização da crise social.

Dentre todas as problemáticas que está acontecendo no país, a que ganhou destaque devido à grande insatisfação popular, foi a crise de abastecimento de produtos básicos, como alimentos e medicamentos, além de incessante corte de energia em todo o território venezuelano. No entanto, todas essas dificuldades deram início a um acentuado processo de migração.

Segundo a OIM - Organização Internacional para Imigração - (2015), a crise econômica no atual governo da Venezuela provocou mudança nos destinos dos venezuelanos, tendo como maior procura os países da América do Sul. Assim o Brasil é 


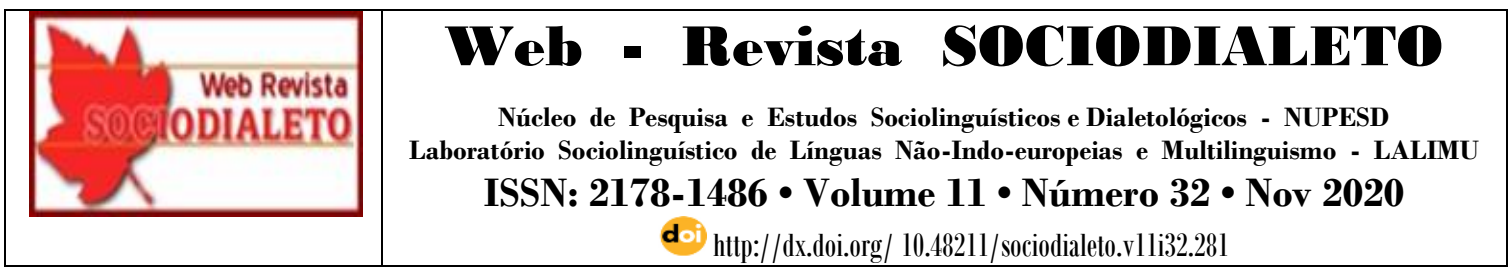

o que mais se destaca ainda que as oportunidades não sejam as melhores e o processo migratório se torna mais facilitado as fronteiras que o país tem com o Brasil. Por exemplo Boa vista, capital de Roraima, se encontra a menos de $200 \mathrm{~km}$ da fronteira brasileira com a Venezuela (RODRIGUES, 2006)

Dados do Instituto Brasileiro de Geografia e Estatística (IBGE), entre os anos de 2015 e 2017 cerca de 20,5 mil venezuelanos migraram para o Brasil através de Roraima, e esse número pode chegar a 79 mil até o ano de 2022. Em 2015, havia cerca de mil venezuelanos vivendo no país, ou seja, em apenas três anos, essa população aumentou $3.000 \%$. Esse aumento se relaciona com a piora da crise política e socioeconômica (QUEIROZ, 2018) vivida na Venezuela.

O Brasil não é escolhido como destinos dos refugiados apenas pela agilidade de atravessar a fronteira, mas também pela facilidade de se solicitar o refúgio, que no Brasil é gratuito, e por terem (a partir do momento de deferimento do pedido) direito a permanecia e benefícios de qualquer cidadão nativo como atendimento no Sistema Único de Saúde - SUS, moradia temporária e não ser deportado (SIMÕES, 2017; QUEIROZ, 2018).

Segundo Simões (2017) e Queiroz (2018), o aumento de pedidos de refúgio pode ser resultado das limitações e restrições crescentes encontrada pelos imigrantes para entrar em países da União Europeia e Estados Unidos, além de pode ser um reflexo das políticas de migração brasileira em que solicitar o refúgio formalmente é mais seguro.

Apesar de todas as facilidades encontradas pelos refugiados um obstáculo está presente desde o início do processo, são as barreiras linguísticas. Ainda que a língua portuguesa e o espanhol, idioma oficial da Venezuela, apresentem algumas semelhanças, os imigrantes que não conhecem o português sentem mais dificuldade para se integrarem no novo país. Isso faz com que ocorra uso misto (castelhano e português) em suas falas, e ganha maior destaque nos cartazes que produzem com a finalidade de conseguirem estabilidade financeira (esses cartazes são pedidos de ajuda para conseguirem emprego). 


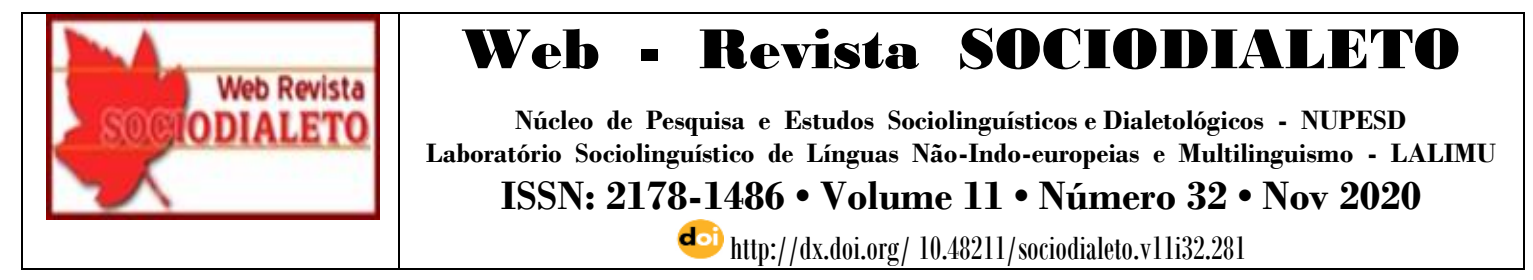

Tentando minimizar essa barreira, as instituições federais têm criado turmas de língua portuguesa para estrangeiros, que visam desenvolver as habilidades linguísticasdiscursivas que contribuem assim para a inserção dos migrantes no mercado trabalho e universitário (ZAMBRANO, 2016; RIBEIRO, 2018).

Assim o objetivo desse artigo é analisar a ortografia nos cartazes produzidos pelos refugiados venezuelanos, a relação dessa escrita com o seu país de origem e a semelhança com a língua portuguesa, e quais são os traços em comum entre os dois idiomas.

\section{Metodologia}

Este trabalho, inscrito sob a perspectiva descritiva e qualitativa, prevê quatro fases para sua execução: constituição do corpus, entrevista, levantamento do referencial teórico e análise. O corpus será constituído por fotografia, de três cartazes tirada dos venezuelanos que se encontram nas ruas de Cuiabá. Nesses cartazes serão observados os aspectos ortográficos presentes nos cartazes, destacando-se quais as semelhanças da escrita em espanhol em relação a escrita da língua portuguesa. Quanto à entrevista, servirá para analisar a oralidade, e também se tem alguma relação com a escrita da língua portuguesa, assim como na oralidade eles misturam o espanhol com o português se na escrita há a mesma semelhança. Além do levantamento dos dados de cada um dos entrevistados, como idade, nível de escolaridade, idiomas falados por eles, fatos que os levaram a vir morar no Brasil, entre outros.

Com base em Mollica (2019), as línguas apresentam um dinamismo inerente, isto quer dizer que são heterogêneas. Existem formas distintas que, em princípio, se equivalem semanticamente no nível do vocábulo, da sintaxe e morfossintaxe, do subsistema fonético e fonológico e no domínio pragmático-discursivo.

É importante ressaltar que a Sociolinguística é uma das subáreas da Linguística que estuda a língua em uso dentro da comunidade de fala, direcionando toda atenção para 


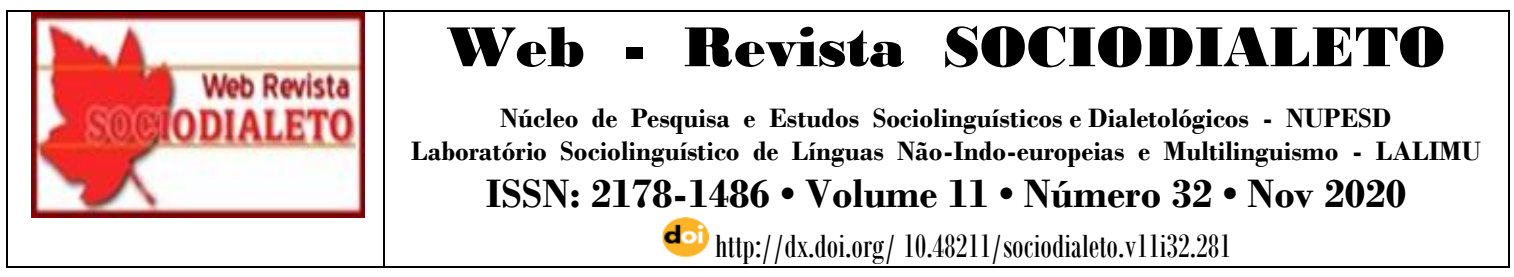

um tipo de investigação que estabelece uma relação de correspondência entre os aspectos linguísticos e sociais.

Para o estudo proposto, faremos um levantamento dos dados coletados na entrevista, e em seguida a análise das características ortográficas observadas na escrita dos cartazes, levantaremos quais fatores levaram à utilizada determinada escrita, uma vez que eles ainda não têm total domínio do idioma brasileiro.

\section{Relatos das Entrevistas}

Para conhecer um pouco da história dos refugiados, no dia 30 de novembro de 2019, demos início a uma entrevista, utilizando a língua portuguesa, uma vez que os entrevistados já tinham um pouco de conhecimento do idioma. Sendo organizada de forma semiestruturada para que as perguntas pudessem ser modificadas de acordo com o contexto e a necessidade dos envolvidos. No primeiro momento da entrevista levantamos os seguintes dados conforme a tabela abaixo:

Tabela 1 - Dados dos Entrevistados

\begin{tabular}{|l|c|l|l|l|l|}
\hline Participante & Sexo & Idade & Pais de origem & Tempo no Brasil & Escolaridade \\
\hline P1 & M & 22 & Venezuela & 2 meses & Ensino Médio \\
\hline P2 & M & 22 & Cuba & 1 mês & Ensino Médio \\
\hline P3 & F & 44 & Venezuela & 20 dias & Ensino Médio \\
\hline P4 & M & 30 & Venezuela & 16 dias & Nível Básico \\
\hline P5 & F & 29 & Cuba & 1 mês & Ensino Médio In \\
\hline
\end{tabular}




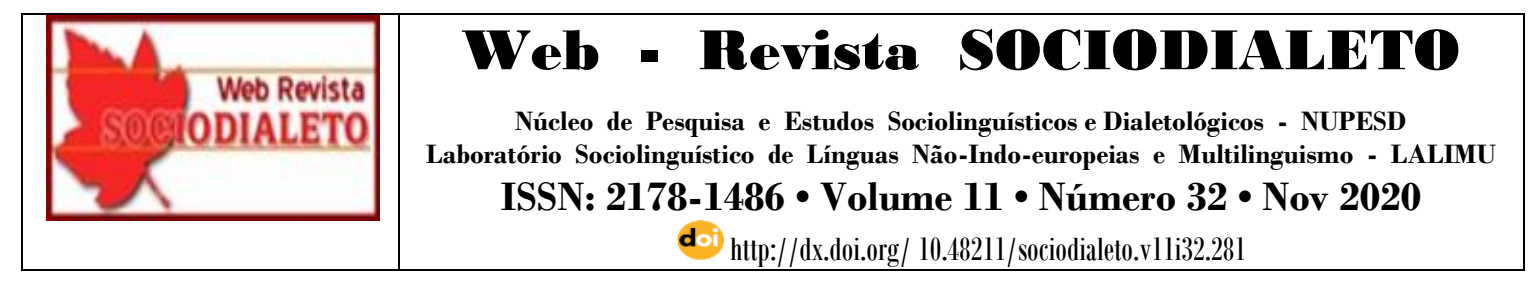

\begin{tabular}{|l|l|l|l|l|l|}
\hline P6 & M & 39 & Bolívia & 40 dias & Ens. Fundamental \\
\hline
\end{tabular}

Fonte: elaborada pelas autoras, 2019.

De acordo com Labov (2008), a observação assistemática ou espontânea, se dá através dados reais, e em ambientes que se encontram vários membros de uma comunidade de fala, e que estejam reunidos de modo que sua fala seja naturalmente e facilmente ouvida pelos outros. Já a observação sistemática acontece de modo anônimo, em conversas que não se definem como entrevistas. Em alguns locais estratégicos, tornando-se possível estudar várias pessoas num breve período de tempo, e se sua identidade social for bem definida pela situação objetiva terá resultados satisfatórios.

Baseando nesse contexto, primeiro deu-se início a entrevista pelo método da observação sistemática com uma conversa informal, conforme a tabela acima, para despertar o desenvolvimento da empatia e conhecer sobre quem estávamos entrevistando, segundo a investigação propriamente dita.

No segundo momento da entrevista, realizamos as seguintes questões:

1.Tem algum motivo para que as crianças e as mulheres tenham de ir às ruas para pedir ajuda e emprego?

R: Dos seis entrevistados, somente um disse que seria para impressionar as pessoas, os demais disseram que não tinham com quem deixar uma vez que eles não conhecem as pessoas do abrigo e não sabem se podem confiar.

2. Existe alguém especifico para fazer os cartazes?

R: Em relação a pergunta sobre a confecção dos cartazes e quem seriam os responsáveis, todos os seis entrevistados responderam que eles mesmos que fazem os cartazes, pois três vezes por semana eles têm aula de português. 


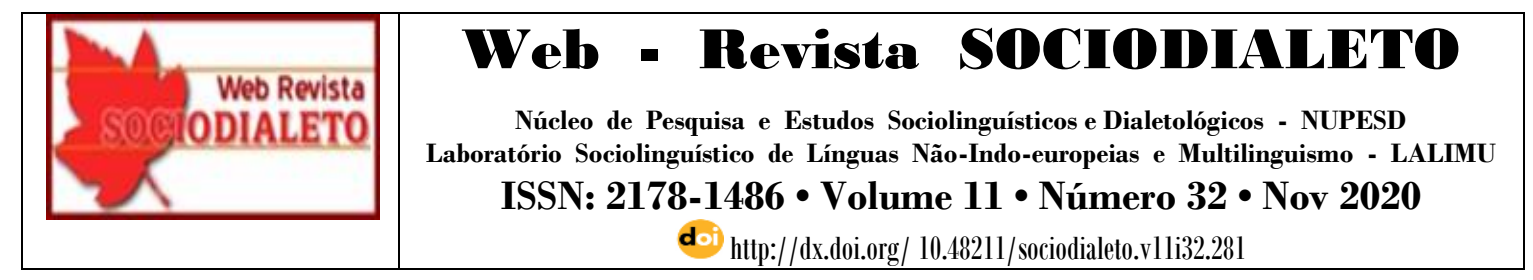

3. Por que utilizar o gênero cartaz para pedir ajuda, de onde veio essa ideia?

R: Dois dos entrevistados disseram por não saberem o idioma, acharam que seria a forma mais fácil de pedir ajuda, os demais relataram que a ideia vem desde o país deles, como forma de chamar a atenção das pessoas.

4. Existe alguma semelhança em relação ao transporte público e assistência à saúde entre os dois países, Brasil e Venezuela?

R: A resposta foi unanime que aqui no Brasil o transporte público é muito rápido e eficiente, tem ônibus toda hora e para todos os lugares, enquanto na Venezuela são muito poucos e em condições precárias de uso. Quanto, a saúde pública, disseram que aqui os medicamentos são gratuitos o que não acontece no país deles.

5. Perguntamos se já conheciam a língua portuguesa e se eles percebem alguma semelhança com o Espanhol?

R: Quanto ao idioma, eles reconhecem certa semelhança com o português, apesar da pronúncia ser um pouco diferente. Somente um dos entrevistados já sabia falar o português e também tinha domínio da língua inglesa. Os demais somente o espanhol sua língua de origem.

\section{Análise dos Cartazes}

Com o intuito de desenvolver a presente analise, fotografamos seis cartazes nas ruas de Cuiabá entre os dias 01 a 20 de novembro de 2019, em pontos onde se encontravam os venezuelanos, geralmente em semáforos. Os cartazes são feitos de papelão, não são muito diversificados normalmente trazem as mesmas citações, solicitando um emprego para manter a família ou uma ajuda de qualquer natureza, e em 


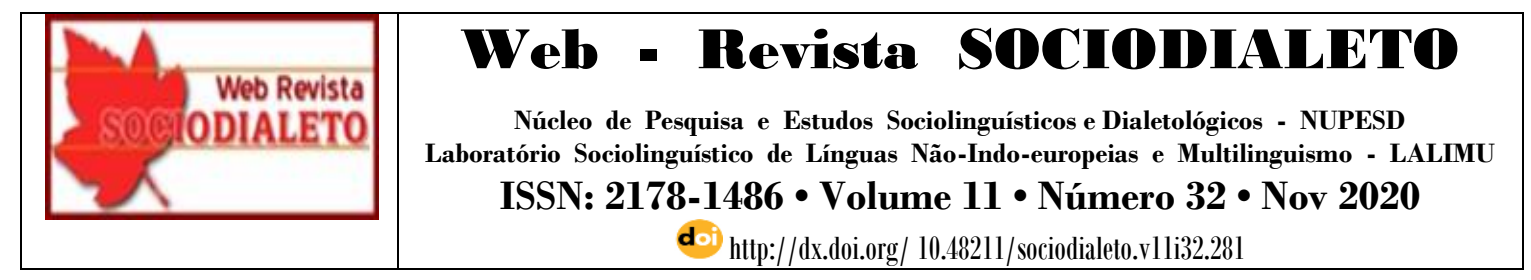

seguida com o contato telefônico, devido a esse fator separamos três cartazes para a análise.

No primeiro cartaz analisado percebesse as seguintes ocorrências, uma mistura do uso da escrita no espanhol com a escrita em português.

Cartaz 1

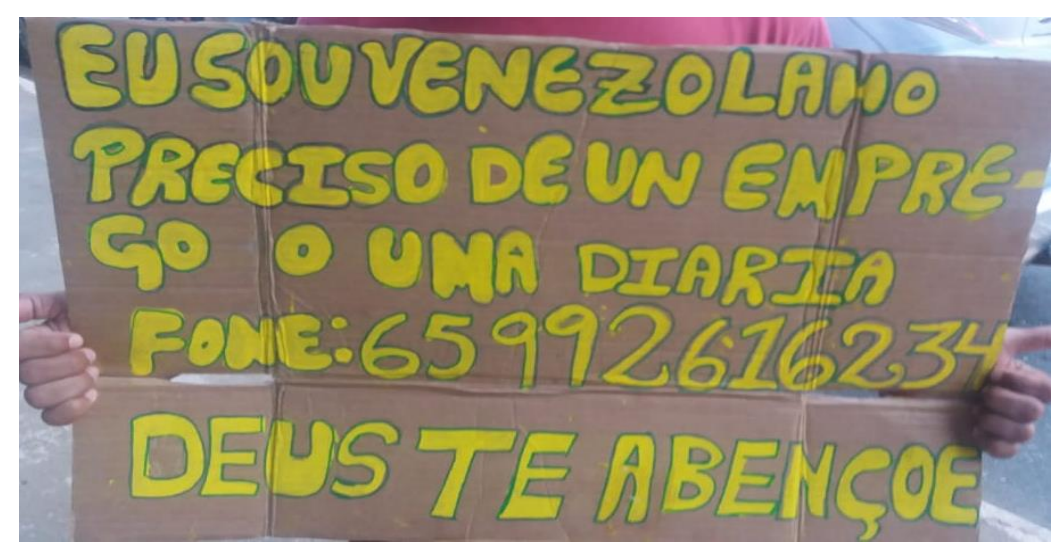

Foto: Ivanete Maria de Jesus - nov/2019

Em algumas palavras a escrita estava de acordo com a norma padrão do português, em outras talvez por desconhecimento da língua portuguesa utilizou-se seu próprio idioma, constituindo-se desta forma:

a. <venezolano> substantivo em espanhol, em português <venezuelano>

b. <un> uso do artigo definido em espanhol, em português <um>

c. $\langle o>$ conjunção alternativa em espanhol, em português <ou>

d. < diaria $>$ sem o acento agudo, por não conhecimento da nossa ortografia.

Cartaz 2 


\begin{tabular}{|c|c|}
\hline $\begin{array}{r}\text { Web Revista } \\
\text { ODIALETO }\end{array}$ & 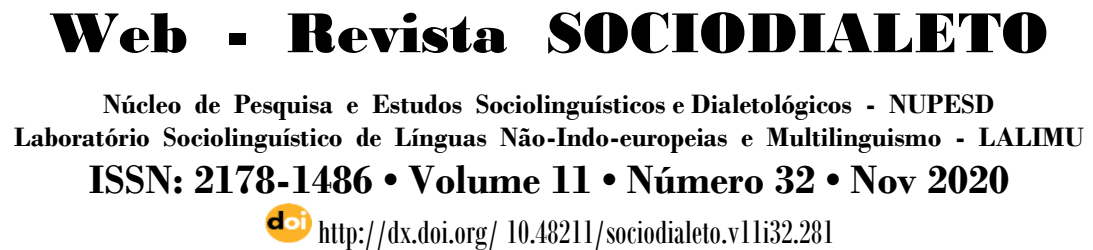 \\
\hline
\end{tabular}

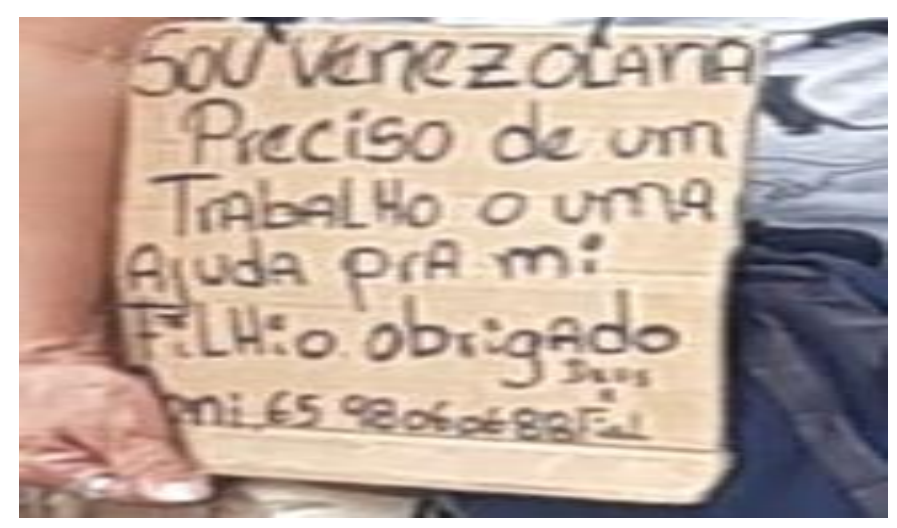

Foto: Ivanete Maria de Jesus - nov/2019

a. $\langle o>$ conjunção alternativa no espanhol, em português seria <ou>

b. $\langle m i>$ pronome possessivo no espanhol, em português seria $<$ meu $>$

c. $\langle$ filhio $>$ escrita conforme a pronuncia, em desacordo com a escrita da norma padrão.

Cartaz 3

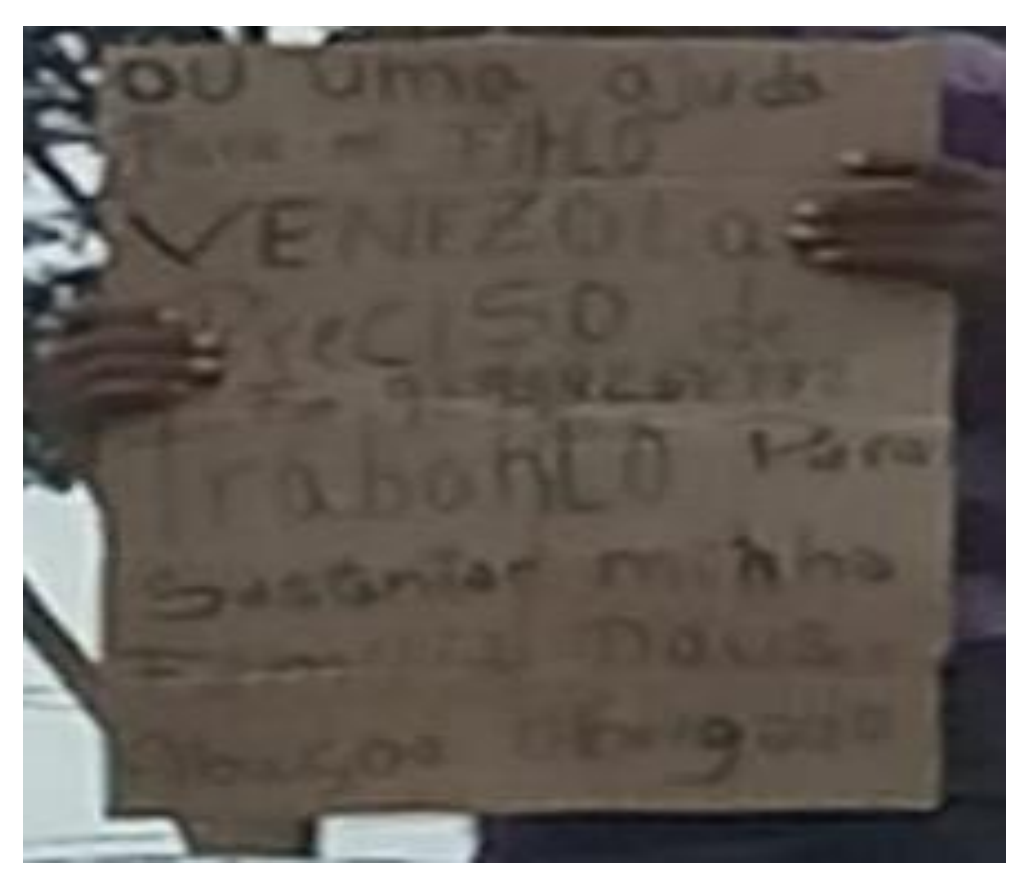

Foto: Ivanete Maria de Jesus - nov/2019 


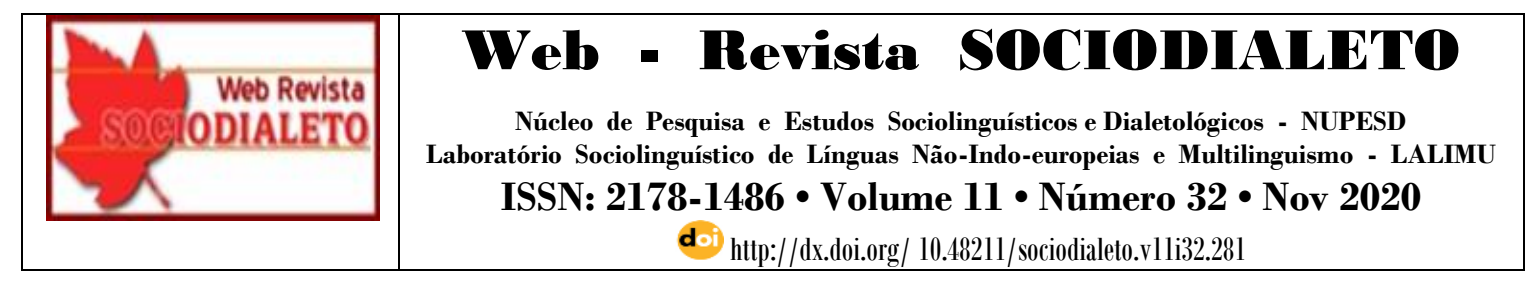

a. $\langle m i>$ pronome possessivo no espanhol, em português seria <meu>

b. <venezolano> escrita em espanhol.

c. $\langle$ trabahlo $>$ escrita com erro de ortografia, quis dizer <trabalho>

d. <soscentar> escrita com erro ortográfico, escrita conforme a sua pronuncia em português, quis dizer <sustentar>. A palavra escrita em espanhol <sostener>, utilizando uma mistura das duas línguas.

\section{Considerações finais.}

Durante a entrevista descobrimos que não existiam somente venezuelanos, como também refugiados de outros países vizinhos como Cuba e Bolívia, todos vieram com um único objetivo, buscar melhores condições de vida para eles e seus familiares que ainda vivenciam a crise que assola seu país de origem.

Interessante ressaltar que maioria dos entrevistados demonstraram satisfeitos por estarem no Brasil, veem possibilidades de melhorar de vida, pois viver com um salário de $\mathrm{R} \$ 30,00$ (trinta reais) estava muito difícil para eles. E que aqui conseguem ver a possibilidade de ter melhor condições financeiras, pois já conseguem enviar até $\mathrm{R} \$ 100,00$ (cem reais) para os familiares, quando fazem algum trabalho extra. Todos eles pretendem buscar a família assim que estiverem trabalhando e tiver um lugar para morar.

A entrevista foi realizada no abrigo Centro Pastoral para Migrantes, onde a permanência deles segue alguns requisitos. Os refugiados podem permanecer no abrigo por um prazo de 45 dias ou até conseguirem regularizar os documentos e conseguirem um emprego formal.

A rotina no abrigo é cheia de metas e limites, tem que acordar cedo e ir em busca de emprego, os alojamentos são separados, para homens, outro para mulheres e outro 


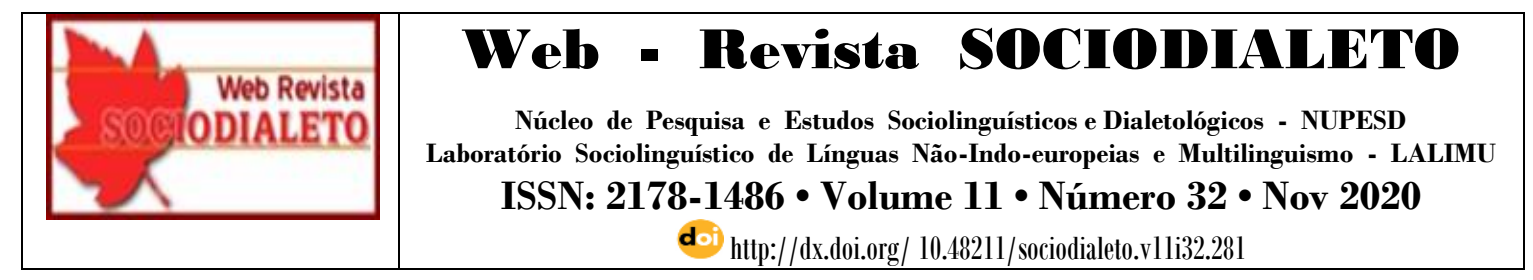

somente para mulheres com crianças, mesmo se tratando de casais não permanecem no mesmo quarto.

Existem banheiros para homens e para mulheres, os banhos se encerram as 21 horas, porque as 22 horas todos devem se recolher. A alimentação é feita pelos voluntários da Igreja Católica, que se revezam durante a semana e finais de semana. Diariamente recebem doações, pois somente assim conseguem manter a casa em perfeito funcionamento para receber os refugiados, o local comporta cerca de 100 pessoas, não é muito sofisticado, porém encontra-se em perfeitas condições de uso.

Fora muito relevante perceber a participação da comunidade, saber que vivemos num país acolhedor que se preocupa com o bem-estar do próximo, que ainda temos pessoas que não estão preocupados somente com a questão capitalista e nas desvantagens que seria abriga-los em nosso país. Outro fator interessante que presenciamos enquanto fazíamos a visita, foram a presença de empresários que também procuram o abrigo a procura de funcionários o que facilita bastante a inserção dessas pessoas no mercado de trabalho.

\section{REFERÊNCIAS}

CALVET, L. J. Sociolinguística: uma introdução crítica. Louis-Jean Calvet; tradução Marcos Marcionilo. São Paulo: Parábola Editorial, 2002, 160 p.

CARDOSO, Suzana Alice. Geolinguística: tradição e modernidade. São Paulo: Parábola editorial, 2010.

IBGE. Projeção da População 2018: número de habitantes do país deve parar de crescer em 2047. Rio de Janeiro, 01 de ago. 2018. Disponível em: $<$ https://agenciadenoticias.ibge.gov.br/agencia-sala-de-imprensa/2013-agencia-denoticias/releases/21837-projecao-da-populacao-2018-numero-de-habitantes-do-paisdeve-parar-de-crescer-em-2047> Acesso em: 19 dez. 2019

LABOV. W. Padrões sociolinguísticos. Willian Labov; tradução Marcos Bagno, Maria Marta Pereira Scherre, Caroline Rodrigues Cardoso - São Paulo, Parábola Editorial, 2008, $392 \mathrm{p}$. 


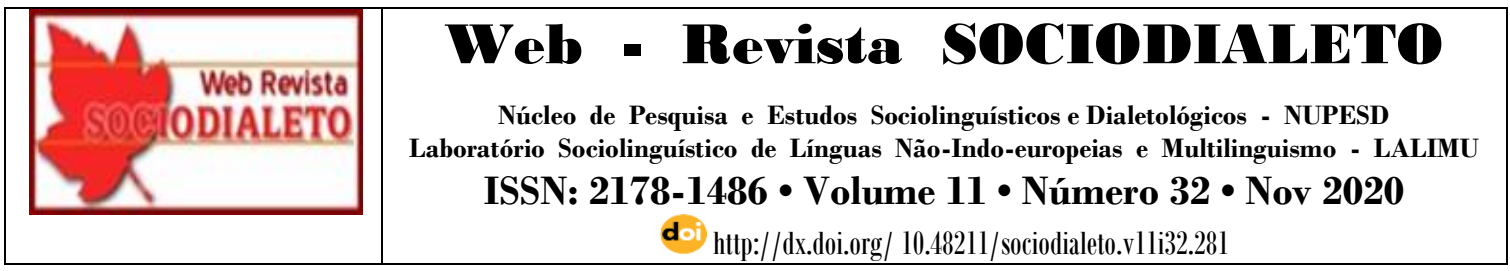

MOLLICA, M. C.; BRAGA, M. L. (Orgs.). Introdução à Sociolinguiística: o tratamento da variação. São Paulo: Contexto, 2008.

OIM. Relatório World Migration Report: Global Migration Trends Factsheet . Jan-Dez de 2015.Disponível em:< http://gmdac.iom.int/global-migration-trends-factsheet $>$. Acesso em: 25 de Jan. de 2020.

QUEIROZ, Christina. Estratégia de Entrada. Jornal da Unicamp, Campinas, 20 de mar. 2018.Edição web. Disponível em: $<$ https://www.unicamp.br/unicamp /ju/noticias/2018/03/20/estratégia-de-entrada>. Acesso em: 25 de Jan. 2020.

RIBEIRO, Lucélia Alves dos Santos. O Papel do Instituto Federal de Mato Grosso na Inserção dos Haitianos na Sociedade. 2018. Dissertação (mestrado em Assessoria de Administração)

RODRIGUES, Francislene. Migração transfronteiriça na Venezuela. Rev. Estudos Avançados: v. 20, n. 57, p. 197-207. 2006

SIMÕES, Gustavo da Frota. Perfil Sociodemográfico e Laboral da imigração venezuelana no Brasil. Curitiba - PR: editora CRV, 2017

VAZ, Alcides Costa. A crise venezuelana como fator de instabilidade regional: perspectivas sobre seu transbordamento nos espaços fronteiriços. Análise Estratégica, n. 3, 2016.

ZAMBRANO,C.E.G.; ARAÚJO, M.S.M. Projeto de Extensão Português para Imigrantes. Pró-reitora de Extensão da Universidade Estadual de Roraima, 2017. 
Núcleo de Pesquisa e Estudos Sociolinguísticos e Dialetológicos - NUPESD Laboratório Sociolinguístico de Línguas Não-Indo-europeias e Multilinguismo - LALIMU ISSN: 2178-1486 • Volume 11 • Número 32 • Nov 2020

Recebido Para Publicação em 04 de junho de 2020.

Aprovado Para Publicação em 30 de agosto de 2020. 